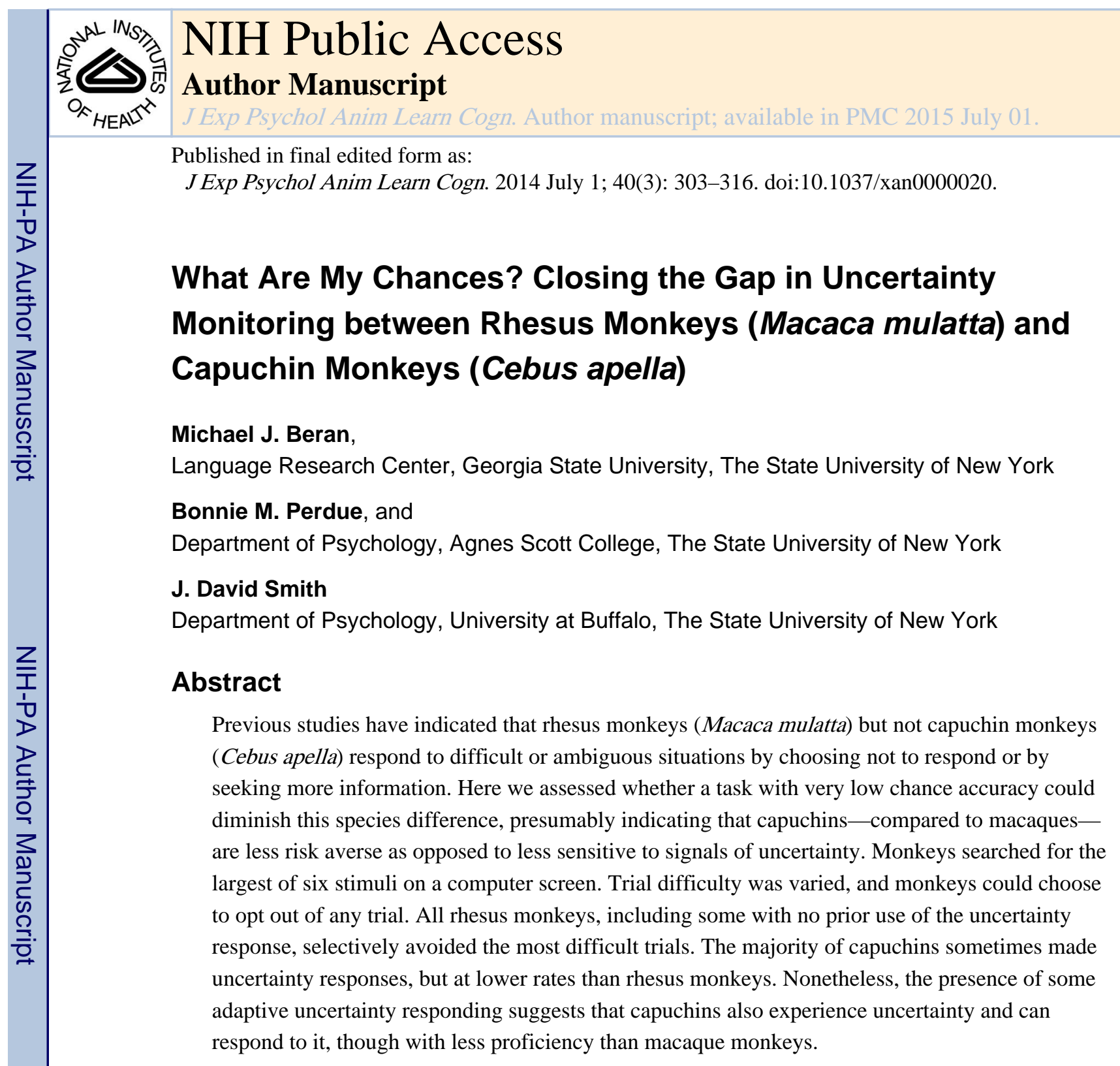

\title{
Keywords
}

uncertainty monitoring; metacognition; rhesus monkeys; capuchin monkeys; comparative psychology; psychophysics

\begin{abstract}
A student freezes in dread reading an essay question - she knows she doesn't know that answer. A diner in a restaurant frantically searches memory — he knows he can't place the name of the acquaintance approaching his table. These situations demonstrate humans' capacity for metacognition - that is, their cognitive awareness of mental states like knowing, uncertainty, and doubt. A large research literature explores this capacity in humans (e.g., Balcomb \& Gerken, 2008; Benjamin, Bjork, \& Schwartz, 1998; Dunlosky \& Bjork, 2008; Flavell, 1979; Koriat \& Goldsmith, 1994; Nelson, 1992; Scheck \& Nelson, 2005; Schwartz, 2008). An active debate centers on the question of whether humans are unique in their
\end{abstract}

Correspondence concerning this article can be addressed to Michael Beran, Language Research Center, Georgia State University, University Plaza, Atlanta, GA 30302. mjberan@yahoo.com.. 
metacognitive abilities, or whether this characteristic is shared with other species (Carruthers, 2008, 2009; Crystal \& Foote, 2009; Hampton, 2009; Jozefowiez, Staddon, \& Cerutti, 2009; Kornell, 2009, 2013; Le Pelley, 2012; Smith, 2009; Smith, Beran, Couchman, $\&$ Coutinho, 2008).

The answer to this question could reveal the earliest evolutionary roots and the waypoints of metacognition's emergence in the primates, and since its inception, animal metacognition research has focused heavily on the performance of primates (Shields, Smith, \& Washburn, 1997; Smith, Shields, Schull, \& Washburn, 1997; Smith, Shields, Allendoerfer, \& Washburn, 1998). This research area is very active now within comparative psychology (e.g., Basile, Hampton, Suomi, \& Murray, 2009; Beran, Smith, Redford, \& Washburn, 2006; Call, 2010; Castro \& Wasserman, 2013; Foote \& Crystal, 2007; Fujita, 2009; Hampton, 2001; Iwasaki, Watanabe, \& Fujita, 2013; Kornell, Son, \& Terrace, 2007; Marsh \& MacDonald, 2012a; Paukner, Anderson, \& Fujita, 2006; Roberts, Feeney, McMillan, MacPherson, \& Musolino, 2009; Smith, Beran, Redford, \& Washburn, 2006; Smith, Coutinho, Church, \& Beran, 2012; Suda-King, 2008; Sutton \& Shettleworth, 2008; Washburn, Gulledge, Beran, \& Smith, 2010), and a number of species have been tested. Among primates, important behavioral contrasts have been seen across different species and different tasks.

\section{Great apes}

Call and Carpenter (2001) devised an information-seeking task in which subjects sometimes had all information needed to locate food, but sometimes needed more information. Chimpanzees and orangutans (and human children, for that matter) performed in a manner consistent with metacognition. Subjects responded immediately when they had full information, but they invested time and effort into seeking more information when more was needed to locate food. This suggests that subjects knew when they already knew the location of food and also knew when they did not (also see Call, 2010; Marsh \& MacDonald, 2012a, 2012b).

Beran, Smith, \& Perdue (2013) added to this paradigm a communicative, symbolic component. They tested language-trained chimpanzees by placing food items in an opaque container. Sometimes the chimpanzees saw the food item placed, other times not. They received the food if they named it correctly on their lexigram symbol keyboard.

Chimpanzees were more likely to visit the food container first—before choosing a lexigram - on trials in which they did not know the container's contents. They were more likely to immediately name the item on the keyboard - without looking into the container-on trials in which they knew the container's contents. Thus, chimpanzees showed efficient information-seeking behavior that suggested they knew whether they knew the item's identity when it was time to name it.

As the closest living relative of humans, it is not entirely surprising that apes have fared well on metacognitive tasks. All the great-ape species-chimpanzees, orangutans, gorillas, and bonobos - have now shown success in tests of metacognition (Beran et al., 2013; Call, 2010; 
Call \& Carpenter, 2001; Marsh \& MacDonald, 2012a, 2012b; Suda-King, 2008) suggesting that this ability is shared among the taxa.

\section{Macaques}

Rhesus monkeys have succeeded in information-seeking tasks of the type used by Call and others (Hampton, Zivin, \& Murray, 2004). They have succeeded in computer-based information-seeking tasks devised by Beran and Smith (2011). They have shown evidence of metamemory - choosing adaptive behaviors based on the strength of internal memory representations (e.g., Hampton, 2001). They have shown evidence of uncertainty monitoring during multitasking (Smith, Redford, Beran, \& Washburn, 2010) and during tests of Harlow's learning set (Washburn, Smith, \& Shields, 2006).

Finally, rhesus monkeys have shown evidence of uncertainty monitoring in psychophysical tasks. In these tasks, on which the present tasks are based, subjects are presented with a psychophysical discrimination. For example, if pixel density is the relevant dimension, the stimuli would range from sparsely pixelated to densely pixelated, including many steps between. When a stimulus is presented, the subject would be asked to make a dichotomous sparse-or-dense classification of the stimulus. Stimuli near the sparse-dense breakpoint of the discrimination will be most difficult and cause errors. However, subjects in these tasks are also given an uncertainty response (UR) with which they can opt out of any trial they choose. This response need not bring any reward and can be designed to operate only to end a given trial and bring the next randomly chosen trial instead. In this way, subjects may be able to cope with difficulty and even report uncertainty behaviorally. If subjects can monitor the signal of their own uncertainty as they face a difficult, near-breakpoint trial, then they can decline the trial and avoid the risk of error. Rhesus monkeys use the UR appropriately and adaptively, and even isomorphically with the way that consciously metacognitive humans use it (e.g., Smith et al., 2006, 2007). Thus, for many empirical reasons, there is a growing theoretical consensus that macaques show a close analog to humans' uncertainty awareness and a form of metacognitive monitoring. For example, Roberts et al. (2009, p. 130) concluded that—substantial evidence from several laboratories converges on the conclusion that rhesus monkeys show metacognition in experiments that require behavioral responses to cues that act as feeling of knowing and memory confidence judgments. $\|$

Of course the role of associative learning in these paradigms continues to be of theoretical interest (Hampton, 2009; Smith, 2009; Smith et al., 2008; Smith et al., 2009; Smith, Beran, $\&$ Couchman, 2012) and there are ongoing efforts to produce formal models that reproduce macaques' uncertainty performances (e.g., Jozefowiez, et al., 2009; Le Pelley, 2012). These models were discussed extensively in a recent target article (Smith, Couchman, \& Beran, in press a) and commentaries (Basile \& Hampton, in press; Carruthers, in press; Le Pelley, in press; Smith, Couchman, \& Beran, in press b).

Smith et al. (in press a, also Smith et al., 2008) showed that associative models cannot capture certain ccrucial phenomenon in this area. For example, Smith et al. (2006) gave a macaque monkey a density discrimination task along with an uncertainty response that allowed the monkey to avoid making a classification of density. Unlike in studies that 
provide trial-by-trial feedback, in this task four trials were completed before any feedback was given, and then such feedback was rearranged to group rewards and timeouts rather than give feedback in an order that matched response order. The result was that the macaque's subjective uncertainty region displaced away from the discrimination's true breakpoint (Smith et al., 2006). Although LePelley (2012) reported that an associative model also could produce such a displacement, that outcome occurred only when uncertain responses were the dominant responses made by the simulated subject, which does not match the performance pattern of the actual monkey (see Smith et al., in press). Associative models are locked to the task's associative structure. Subjective uncertainty is not. Smith et al. (2008) discussed the problematic instability of associative models of uncertainty responding. These models can produce qualitatively different performance patterns based on just 2 chance occurrences early in a 6,000-trial simulation run. Smith et al. pointed out that Le Pelley's simulations of Hampton's (2001) metamemory data embodied a mistake about the reinforcement structure of that task, rendering those published simulations theoretically unhelpful. (In personal communications, Le Pelley acknowledged this mistake, while suggesting that the model might still apply once the mistake was remedied.)

Smith and colleagues also showed that associative models could not apply to other demonstrations of macaque metamemory (e.g., Smith et al., 1998) without being granted up to 9 freely varying fitting parameters. With this many free parameters, a model could become an empty mathematical abstraction that has little bearing on anything psychological. Even with the 5 free parameters in Le Pelley's (2012) model, this is already a serious concern. Smith et al. also pointed out that associative models cannot explain Smith et al.'s (2012) demonstration that uncertainty responses are psychologically different from the primary perceptual responses in uncertainty tasks because they are more heavily dependent on working-memory resources. Le Pelley (in press) was not able to address this important failure of associative models that was discussed in depth in Smith et al. (in press a).

Basile and Hampton (2013) concluded that Smith et al. (in press a) persuasively identified the problems with current associative models. They agreed that — the associative models proposed by Le Pelley et al. and Jozefowiez et al. do not currently explain the breadth of nonhuman metacognitive performance.|| Carruthers (in press) endorsed Smith et al.'s (in press a) evaluations of associationist explanations in this area. Pointedly, he said: - an obsessive focus on associationist accounts of animal behavior impedes progress in comparative psychology and obstructs attempts to understand animal precursors and homologies of components of human cognition.|| Regarding apes and macaques, therefore, it is largely agreed that they have an analog to humans' uncertainty system and that this system may be a form of metacognitive monitoring. Obviously, this does not imply that their uncertainty system is identical in every conscious and self-reflective way to that in humans (Carruthers, in press; Smith et al., in press b). In fact, understanding these likely differences will be an important task for the field of comparative metacognition, for such differences could illuminate the emergence of reflective minds during primate evolution. 


\section{Capuchin monkeys}

This conclusion does not yet extend to primates broadly. Capuchin monkeys (Cebus apella), a New World primate species, represent another primate lineage. Basile et al. (2009) adapted Call and Carpenter's (2001) food- concealment paradigm for capuchins. Unlike rhesus monkeys, their capuchin monkeys showed minimal evidence of adaptive informationseeking behavior. Paukner et al. (2006) tested capuchins in a similar paradigm. The monkeys searched bent food tubes uselessly (because the bait could not possibly be seen in a visual search). They searched clear tubes unnecessarily (because the baited tube was obvious). Thus, capuchins' behavior contrasted with that of macaques, apes, and humans. Fujita (2009), adapting Hampton's (2001) metamemory paradigm, provided a third demonstration of capuchins' tenuous response to internal psychological signals of uncertainty and doubt. Likewise, in the computer-based information-seeking tasks of Smith and Beran (2011), capuchins did not show strong evidence that they would seek only the necessary information needed for correct performance, whereas rhesus monkeys did.

Finally, Beran, Smith, Coutinho, Couchman, and Boomer (2009) tested capuchins' uncertainty monitoring using the sparse-dense discrimination task already described. Capuchin monkeys, again very unlike rhesus monkeys, essentially never responded uncertain. They did not do so even when the penalty for an incorrect response was raised from a $20 \mathrm{~s}$ timeout to a $90 \mathrm{~s}$ timeout, so that capuchins potentially sacrificed the opportunity for 30 trials and 30 food rewards for every discrimination error they made. Thus, Beran et al. provided another converging line of evidence that the uncertainty- monitoring capacities of capuchins and macaques are different.

These differences between capuchin monkeys and rhesus monkeys across a variety of tasks could be important for revealing a fundamental discontinuity in the phylogenetic distribution of metacognition. They raise the possibility that metacognition may have emerged selectively as a characteristic of the Cattarhine primates. It is exciting that we might place an evolutionary pushpin onto the phylogenetic map identifying where metacognition emerged (i.e., approximately 30 million years ago before Old World monkeys split from apes and humans). However, potential extraneous factors should be carefully considered before pressing this assertion. That is, one must consider whether there are methodological aspects of these tasks that might produce species differences without there being a species discontinuity in the domain of cognitive awareness.

In the present article, we examined one important methodological facet of uncertainty tasks. The standard uncertainty task that we have used (e.g., Smith et al., 1997; Beran et al., 2009) provides a subject with two response options in addition to the UR. Subjects have a 50\% chance of being correct even given random responding. It could be that macaques and capuchins have different set points for risk-taking and risk- aversion behaviors. A 50\% chance of reward might be an acceptable level of —risk $\|$ for a capuchin monkey, but not for a rhesus monkey. In that case, capuchins would naturally not make URs in these tasks, but macaques would. In short, capuchin monkeys may not use responses that allow them to avoid primary classifications on standard tasks because they are more tolerant of 50\% reward, and not because they lack a metacognitive capacity. 
To examine this possibility, we created new psychophysical discriminations in which the probability of reward based on random responding was less than $50 \%$. We did this by having monkeys seek a correct response from among six options, not from among two options as in the standard tasks. If the previously observed species differences represent true differences in uncertainty monitoring, then we would expect those differences to remain intact even in our low-probability paradigm. Alternatively, if the observed species differences reflect different tolerances for risky, exploratory behavior, then we would expect the species differences to be less pronounced. The latter finding would suggest than the species differences in uncertainty monitoring are more quantitative than qualitative in nature, and that one needs to consider carefully the kind of tasks presented across species that can assess uncertainty monitoring comparably and equitably.

The paradigm used here was an extension of a basic uncertainty paradigm, the perceptual psychophysical paradigm that originated the field of animal metacognition (e.g., Smith et al., 1995; Smith et al., 1997). This paradigm — like every human- and animal-metacognition paradigm —is imperfect (see Hampton, 2009; Smith et al., 2012). Our purpose was to foster capuchins' uncertainty responding in a task in which they have demonstrably failed previously to respond uncertain, and to ask whether their uncertainty-response capacity has sometimes been underestimated. Our purpose was not to definitively prove capuchin metacognition by choosing the most sophisticated possible paradigm (a choice on which there would not even be agreement across researchers).

\section{Experiment 1}

\section{Methods}

Participants-We tested six adult rhesus macaques (Macaca mulatta; all males, ages 10 to 26 years) and eight adult capuchin monkeys (Cebus apella; 5 males and 3 females, ages 5 to 23 years). All monkeys had previously been trained to use a joystick with their hands to control a cursor on a computer screen (see Evans, Beran, Chan, Klein, \& Menzel, 2008; Richardson, Washburn, Hopkins, Savage-Rumbaugh, \& Rumbaugh, 1990). They all had participated in numerous previous computerized experiments (e.g., Beran, 2007, 2008; Beran, Evans, Klein, \& Einstein, 2012; Beran \& Parrish, 2012, 2013), including participation by most of these animals in previous related tests (e.g., Beran \& Smith, 2011; Beran et al., 2009; Smith et al., 2006; Smith, et al., 2010). The monkeys had continuous access to water and worked for fruit flavored food pellets. They also received a daily diet of fruits and vegetables independent of the amount of work they completed on the task, and thus they were not food deprived for the purposes of this experiment. The experiments were conducted with approval of the Georgia State University Institutional Animal Care and Use Committee and followed all federal guidelines.

Apparatus-The monkeys were tested using the Language Research Center's Computerized Test System which consists of a personal computer, digital joystick, color monitor, and pellet dispenser (Evans et al., 2008; Richardson et al., 1990). Monkeys manipulated the joystick with their hands to produce isomorphic movements of a small cursor on the computer screen. Contacting stimuli with the cursor sometimes resulted in the delivery of 45-mg (capuchins) or 94-mg (rhesus) banana-flavored chow pellets (Bio- Serv, 
Frenchtown, NJ) via a pellet dispenser that was connected to the computer through a digitial I/O board (PDISO8A; Keithley Instruments, Cleveland, $\mathrm{OH}$ ). The task program was written in Visual Basic 6.0.

Design and procedure-Each computerized session consisted of a training phase and a test phase, and monkeys completed as many trials as they chose during daily sessions that lasted from 2 to 6 hours. During the training phase of each session, monkeys initially saw two squares on the computer screen, presented in one of six designated locations that formed a rough semicircle on the screen from bottom left upward and then back down to the bottom right part of the screen (Figure 1). These squares were presented in widths and heights measured in twips in Visual Basic. Each twip is $1 / 567 \mathrm{~cm}$. Monkeys moved a cursor that was centered on the screen into contact with one of those squares. The cursor moved at approximately $5 \mathrm{~cm}$ per second when the joystick was fully displaced in a direction. If the selected square was the largest, the monkey heard a melodic chime (approximately 1.5 seconds in duration) and received a single food pellet. If another square was selected, a buzz tone sounded (approximately 1.5 seconds in duration), no food was given, and a 30 second time-out period occurred during which the screen remained blank. A new trial was then presented after a $1 \mathrm{~s}$ inter-trial interval. The location of the largest square on the screen was randomly determined on each trial from one of the six possible locations, with no restrictions on how many trials in a row this might occur.

After reaching a criterion of 17 trials correct in the most recent 24 trials, three squares appeared onscreen instead of two, and as criterion was met again that number increased, up to a maximum of six squares onscreen. The position of the largest square in the semicircle of squares was determined randomly on each trial. The size of the largest square on each trial was chosen randomly to be one of 13 sizes, ranging from 1000 twips per side to 2200 twips per side, in 100 step increments $(1000,1100, \ldots, 2200)$.

There were two methods for choosing the sizes of the foil squares that accompanied the target, largest square. In the All Foils Different Condition, the next closest square to the target was from 75 twips (Level 3) to 550 twips (Level 22) less wide and less high compared to the target. All remaining squares presented on trials in this condition were, successively, 25 twips less wide and less high than the previous foil square. So, for example, if the target was 2000 twips per side, and the trial was a Level 5 trial, the foil squares had heights/widths of 1875 (2000 - 5 X 25), 1850, 1825, 1800, and 1775 twips. All these squares were randomly assigned their screen position.

In the All Foils Same Condition, all foil squares were the same size on a given trial, from 25 twips (Level 1) to 500 twips (Level 20) less wide and less high than the target. Thus, in both conditions, difficulty varied across trials as a function of the level randomly chosen for the first foil square. In addition, trials were generally more difficult in the All Foils Same Condition, because all foil options were the same size and no individual foil stimuli could be more readily discounted as the correct choice than other foil stimulus. In the All Foils Different condition, the variability in size across foils made some of them easier to discount as not being the largest. 
Throughout testing, the UR was present at the bottom center of the screen, and could always be accessed as a response option by the monkeys. Its selection led to the clearing of the screen and the presentation of the next trial. No food pellet, timeout, or auditory feedback was given. The next trial was not guaranteed to be easier or harder than the present trial, and so the UR operated solely as a means of not making the primary discrimination to a given trial. During the test phase, approximately $15 \%$ of trials involved mandatory selection of that stimulus, so that the monkey would experience its effects. These forced-UR trials were randomly selected and could occur for any Level, so they were not specifically presented on trials for which they were optimal to use. During these trials, the cursor would only move downward on the screen and into contact with the question mark. Any other directional movement of the joystick had no effect on the cursor.

Monkeys completed variable numbers of test sessions weekly, depending on their participation in other (unrelated) experimental tasks, and during sessions of this experiment, they completed as many trials as they chose in 4-hour test sessions while also having the opportunity to disengage the task and attend to other things in the home cage area such as enrichment devices or other animals within view. Thus, monkeys completed variable numbers of trials, but all monkeys continued working on the task until a sufficiently large number of trials were collected for performing analyses across the range of trial difficulty levels that we had established.

\section{Results}

Data analyses were restricted to only the testing phase data from the sessions in which six squares were present on each trial. Trials in which the UR was mandatory were excluded from analysis. Table 1 gives trial counts for the analyzed test data from each monkey.

Figure 2 presents the overall performance patterns for each species as a function of the 18 shared levels (levels 3-20) that were presented in the two test conditions. Group-level analyses were conducted using repeated measures analysis of variance, with Level and Condition as within-subject factors and species as a between-subjects factor. First, we examined performance when monkeys chose to attempt the discrimination trial by choosing one of the squares rather than the UR.

The ANOVA indicated that there was a main effect of Level, $F(17,204)=196.29, p<.001$, $\eta_{\mathrm{p}}{ }^{2}=.94,95 \%$ CIs $=.92, .95$. Performance in the primary discrimination task improved as Level increased and the presented trials were easier. There was a main effect of Condition, $F(1,12)=300.93, p<.001, \eta_{\mathrm{p}}{ }^{2}=.96,95 \%$ CIs $=.88, .98$. Performance was better in the All Foils Different Condition in which more of the foils were more easily rejected as possible answers. There was no main effect of Species, $F(1,12)=.63, p=.44, \eta_{\mathrm{p}}{ }^{2}=.05,95 \%$ CIs $=$ $<.001, .34$.

There was a significant interaction of Level and Condition, $F(17,204)=19.50, p<.001, \eta_{\mathrm{p}}{ }^{2}$ $=.62,95 \%$ CIs $=.51, .65$. The effect of level on performance was stronger in the All Foils Same condition. There was a significant interaction of Condition and Species, $F(1,12)=$ $5.99, p=.031, \eta_{\mathrm{p}}{ }^{2}=.33,95 \% \mathrm{CIs}=<.001, .60$. Capuchin monkeys performed relatively more similarly than macaques across the two conditions. There was not a statistically 
significant interaction between Level and Species, $F(17,204)=1.37, p=.15, \eta_{\mathrm{p}}^{2}=.10$, $95 \% \mathrm{CIs}=<.001, .11$, and there was no three-way interaction, $F(17,204)=1.16, p=.30$, $\eta_{\mathrm{p}}{ }^{2}=.09,95 \%$ CIs $=<.001, .09$.

Next, we examined monkeys' use of the UR to decline trials. The ANOVA indicated that there was a main effect of Level, $F(17,204)=19.16, p<.001, \eta_{\mathrm{p}}{ }^{2}=.62,95 \%$ CIs $=.50, .65$. The UR was used more for lower (objectively more difficult) trial levels. There was a main effect of species, $F(1,12)=6.95, p=.022, \eta_{\mathrm{p}}{ }^{2}=.37,95 \%$ CIs $=.00, .62$. Figure 2 clearly shows that capuchins used the UR far less than the macaques did. There was a main effect of condition, $F(1,12)=22.19 p=.001, \eta_{\mathrm{p}}^{2}=.65,95 \% \mathrm{CIs}=.21, .79$. The macaques-at least - used the UR more in the All Foils Same condition. All two-way interactions were significant: Level and Condition, $F(17,204)=4.39, p<.001, \eta_{\mathrm{p}}{ }^{2}=.27,95 \%$ CIs $=.11, .31$; Condition and Species, $F(1,12)=10.94, p=.006, \eta_{\mathrm{p}}^{2}=.48,95 \% \mathrm{CIs}=.05$, .69; Level and Species, $F(17,204)=10.43, p<.001, \eta_{\mathrm{p}}^{2}=.47,95 \% \mathrm{CIs}=.32, .51$, and there was also a significant three-way interaction, $F(17,204)=1.77, p=.034, \eta_{\mathrm{p}}^{2}=.13,95 \%$ CIs $=<.001$, . 15.

Thus, rhesus monkeys used the UR much more often than capuchin monkeys, and they did so across a wider range of trial levels than did the capuchin monkeys. However, capuchin monkeys apparently did use the UR slightly, and used it when it was most appropriate. Figure 2's aggregate graphs could not convey whether many capuchins made URs slightly, or whether a few capuchins made URs generously. Therefore, we also examined the performance of individual monkeys in more detail to better understand the extent and nature of the similarities and differences between individuals and between species.

Figures 3 and 4, respectively, present the individual data for each rhesus monkey and each capuchin monkey for all trial levels. Four of six rhesus monkeys showed a robust use of the UR for the hardest trial levels. All rhesus monkeys showed a statistically significant negative correlation across trial difficulty levels between the percentage of trials that were correct when they chose one of the squares and the percentage of trials on which they chose the UR (Table 1). One capuchin monkey (Griffin) showed a robust use of the UR at difficult trial levels. Six of eight capuchin monkeys (including Griffin) showed a statistically significant negative correlation between URs and correct percentages across trial levels (Table 1). It is important to say that this correlation overlooks the absolute level of URs, and that significant and even strong correlations could result from this analysis no matter how small the actual level of URs was. Nonetheless, many of the individual animals in both species used the UR appropriately for difficult trial levels when they chose it, although qualitatively one can see in the figures that capuchin monkeys made far fewer URs than did rhesus monkeys.

\section{Discussion}

The results of the present experiment are much in line with previous reports assessing the uncertainty-monitoring capacities of rhesus monkeys and capuchin monkeys. The rhesus monkeys in this experiment often used the UR and did so especially on those trials in which they were at greatest risk of making an error. The manipulation of lowering the chance probability of responding to the correct stimulus led to all rhesus monkeys showing typical 
levels of uncertainty responding, or even use of the UR in some cases at very high levels. Some rhesus monkeys that have failed to use the UR, or used it only minimally, in past experiments used it often here, and highly proficiently. For example, Lou is often reluctant $\|$ to use the UR relative to other rhesus monkeys in our past experiments (e.g., Smith et al., 2010), and yet here he used it often.

Capuchin monkeys also had shown little or no use of the UR in past psychophysical discrimination tasks, even though they had had no trouble including a third response within a task if it was another perceptual response like Sparse and Dense. Here we saw once again a very strong species difference in the overall level of adaptive uncertainty responding. However, we saw some capuchin monkeys producing performance patterns that were qualitatively more like those of rhesus monkeys. Some capuchins did show a UR pattern in which they used the UR most often on the most difficult trials. Perhaps the present lowprobability paradigm did begin to foster more URs in these monkeys. These data, along with the success of all macaques in showing that pattern, indicates that tasks in which chance levels of responding are as high as 50\% may not elicit cognitive monitoring and adaptive response patterns as strongly as do low-probability paradigms.

One possibility, then, for the species difference seen between capuchins and rhesus monkeys, is that capuchin monkeys are less risk sensitive than rhesus monkeys. For capuchins, the chance for food reward may outweigh the aversion of timeouts. Beran et al. (2009) did take this possibility into account, at least partially, when they greatly increased the timeout period, and that manipulation did foster some use of the UR, although only from one monkey. However, that manipulation did not increase the chances of a timeout, but rather its duration, whereas here a change to the chance of suffering a timeout (at least for the hardest levels) did seem to evoke some URs from more monkeys in the present experiment.

\section{Experiment 2}

To assess whether capuchin monkeys might increase their URs under some circumstances, we conducted a second experiment. We focused on the macaques and on the four capuchin monkeys (Griffin, Logan, Nkima, and Widget) that had made URs more generously in Experiment 1, to allow the latter species to make the strongest uncertainty-monitoring statement possible. We restricted testing to the All Foils Same condition only, creating an environment of maximum difficulty that might maximally foster uncertainty responding. We manipulated the availability of the UR across trials, sometimes allowing URs and sometimes requiring animals to complete discrimination trials. This created an environment of actually experienced errors and timeouts that might foster URs so as to avert additional errors and timeouts. This last manipulation also allowed us to differentiate the performance of animals on forced-discrimination trials from that on chosen-discrimination trials. If the latter performance levels were higher, it might signal that animals were choosing to accept trials strategically in a way that improved their overall performance in the primary task itself. 


\section{Methods}

Participants-We tested the same six rhesus macaques and the four capuchin monkeysGriffin, Logan, Nkima, and Widget)—that had shown the highest levels of URs in Experiment 1.

Apparatus-The apparatus was identical to that in Experiment 1.

Design and procedure-Monkeys now always started each session with all six rectangles available on each trial. Only trials within the All Foils Same condition were presented, maximizing task difficulty. The essential difference in the procedure now was that animals received both forced-discrimination trials (with no UR available and no way to decline the trial) and optional-discrimination trials (with the UR available so that animals only completed the discrimination if they chose to). Each trial was randomly determined to be a Forced trial or an Optional trial with equal probability (50/50).

In Experiment 2, the macaques received no trials in which they were required to use the UR, because this fostering technique was clearly not necessary for them any longer given performance in Experiment 1. Capuchin monkeys still received approximately $15 \%$ of trials requiring completion by the UR, once again to foster their strongest use of this response. These trials were excluded from analysis once again. All other aspects of the task were the same as in Experiment 1.

\section{Results}

Table 1 gives trial counts for the analyzed test data from each monkey. Figure 5 presents the overall performance patterns and patterns of UR use for each species as a function of level (1-20) presented in the two test conditions.

First, we examined performance when monkeys chose to attempt the discrimination trial by choosing one of the squares. The ANOVA indicated that there was a main effect of Level, $F(19,152)=319.12, p<.001, \eta_{\mathrm{p}}^{2}=.98,95 \% \mathrm{CIs}=.96, .98$. Performance in the primary discrimination task improved as Level increased and the presented trials were objectively easier. There was a main effect of Condition, $F(1,8)=8.27, p=.021, \eta_{\mathrm{p}}{ }^{2}=.51,95 \%$ CIs $=$. $01, .73$. Performance was better in the UR Available condition than in the UR Unavailable condition. There was a main effect of Species, $F(1,8)=7.43, p=.026, \eta_{\mathrm{p}}{ }^{2}=.48,95 \%$ CIs $=<.001, .72$. Capuchin monkeys performed better.

There was a significant interaction of Level and Condition, $F(19,152)=2.31, p=.003, \eta_{\mathrm{p}}{ }^{2}$ $=.22,95 \% \mathrm{CIs}=.03, .24$. The effect of level on performance was more pronounced in the UR Unavailable condition. There was a statistically significant interaction between Level and Species, $F(19,152)=6.47, p<.001, \eta_{\mathrm{p}}^{2}=.45,95 \% \mathrm{CIs}=.26, .48$. Capuchin monkeys performed better across the hardest levels compared to rhesus monkeys. There was not a significant interaction of Condition and Species, $F(1,8)=1.32, p=.28, \eta_{\mathrm{p}}^{2}=.14,95 \% \mathrm{CIs}=$ $<.001, .50$, and there was no three-way interaction, $F(19,152)=1.22, p=.25, \eta_{\mathrm{p}}^{2}=.13$, $95 \%$ CIs $=<.001, .13$. 
Next, we examined monkeys' use of the UR to decline trials in the UR Available condition. The ANOVA indicated that there was a main effect of Level, $F(19,152)=35.57, p<.001$, $\eta_{\mathrm{p}}{ }^{2}=.82,95 \% \mathrm{CIs}=.74, .83$, but there was no main effect of species, $F(1,8)=3.66, p=$. $09, \eta_{\mathrm{p}}{ }^{2}=.31,95 \% \mathrm{CIs}=<.001, .62$. However, the two-way Level by Species interaction was significant, $F(19,152)=5.36, p<.001, \eta_{\mathrm{p}}^{2}=.40,95 \%$ CIs $=.21, .44$. Rhesus monkeys again used the UR more often than capuchin monkeys across a wider range of trial levels. Nonetheless, there was evidence again that capuchin monkeys did use the UR, and they used it when it was most appropriate.

Data were also analyzed at the level of each monkey. Figures 6 and 7, respectively, present the data for individual rhesus monkeys and capuchin monkeys. Again, we examined the relation between performance (percentage choices correct) when a square was selected and the percentage of trials in which the UR was selected (in the UR Available condition), across all levels of difficulty in each condition. All monkeys showed a statistically significant negative correlation (Table 1).

\section{Discussion}

Experiment 2 produced two noteworthy outcomes. First, as in Experiment 1, all of these monkeys used the UR selectively for those trials on which they were most likely to err. As in Experiment 1, capuchin monkeys used the UR less often and less broadly than did rhesus monkeys, but they did use it, and to a degree that allows for the conclusion that they can show the patterns of uncertainty responding that may be interpreted as reflecting metacognition in other monkey species. Experiment 2 was successful in creating fostering conditions that led capuchin monkeys to use the UR more generously and more adaptively.

Second, Experiment 2 demonstrated the Forced-Chosen effect in which monkeys of both species were more accurate when they completed trials volitionally than when they completed trials mandatorily. This has been taken to reflect metacognitive processes in animals (e.g., Hampton, 2001) because it could indicate that they were monitoring a valid psychological signal of knowing or of confidence as they decided to attempt the trial. This signal simply cannot have any influence on the trials they are forced to complete. Based on this interpretation, and on our finding the Forced-Chosen effect in both species, one could provisionally conclude that rhesus monkeys and capuchin monkeys have some capacity to monitor that psychological confidence signal, though rhesus monkeys apparently monitor that signal more easily and more sensitively.

\section{General Discussion}

The present results clarify a seeming disconnect in uncertainty monitoring among primate species. Previous research has shown that apes and Old World monkeys often succeed in monitoring uncertainty, either by declining difficult perceptual classifications or memory tests (Beran et al., 2006; Hampton, 2001; Smith et al., 1997, 2006, 2010; Suda-King, 2008), seeking information that is needed (e.g., Beran et al., 2013; Beran \& Smith, 2011; Call, 2010; Call \& Carpenter, 2001; Hampton et al., 2004), or accurately assessing their own responses after they have been made (e.g., Kornell et al., 2007). Capuchin monkeys, a New World primate species, showed little or none of these behavioral strategies in their response 
patterns to many of the same tests (Basile et al. 2009; Beran et al., 2009; Beran \& Smith, 2011; Paukner et al., 2006), suggesting that they either did not experience the uncertain states that other primates experience or that they are incapable of mapping those states to behavioral responses that would allow them to deal adaptively with such uncertainty.

Focusing on just one of these previous reports (because it involved many of the monkeys in the present experiment), Beran et al. (2009) showed that capuchin monkeys performed like rhesus monkeys in classifying pixelated boxes as sparse or dense. And, when they were asked to classify stimuli in the middle of the continuum as being objectively —Middle $\|$ stimuli, they quickly learned to do this. However, with the exception of only one animal in one phase of testing, they would not use the UR for difficult trials that fell between sparse and dense endpoints, despite repeated attempts to get them to do so. Macaques do show use of the UR in this circumstance, completing an apparently strong dissociation across species. This dissociation could have strong theoretical implications for the evolution of uncertaintymonitoring capacities in primates, because of the phylogenetic relations of these species to each other, and to humans. We assessed in this experiment the impact on uncertainty responding of relative degrees of risk in the primary classificatory responses the monkeys could make. We hoped in this way to counter capuchins' possible risk tolerance and give them a generous chance to show their best uncertainty-monitoring performance.

In the present experiment, guessing was not profitable by any of the usual standards of the tasks these animals perform (where chance is usually 50\%). Chance level was $16.67 \%$ in this experiment, and so when difficult levels were presented, guessing was far less likely to lead to reward than to punishment. This meant that even a risk tolerant species should decline trials that did not have a clear primary response that — felt $\|$ appropriate to the monkey. We predicted that this might evoke more frequent URs from rhesus monkeys (which it did, with some monkeys declining the large majority of trials for the hardest levels), but also that it might foster URs from capuchin monkeys.

In Experiment 1, rhesus monkeys did make URs often, declining on average $40 \%$ of the most difficult trials. However, many capuchin monkeys did not do so. Only one animal declined difficult trials often. Five of eight animals made URs minimally. As a group, the capuchins declined difficult trials at one-fifth the level of the macaques. Thus, a clear species difference in uncertainty responding was preserved in Experiment 1, despite our effort to narrow it by changing the risk contingencies. Nonetheless, some capuchin monkeys did show the behavioral pattern of declining the most difficult trials, and their use of the UR at least overlapped with that of the rhesus monkeys that least often used the UR. Experiment 1, by changing the risk contingencies, did arrange for the upper and lower ends of capuchin's and macaques' individual differences to at least touch along the uncertain-monitoring continuum. Experiment 2 took additional steps to further foster capuchins' uncertainty responding (further testing of the best performing animals, forced URs to remind about that response, maximally difficult trial environments, and so forth). It succeeded, by fostering three capuchins to decline up to $40 \%$ of the most difficult trials.

Experiment 2 also reproduced the important Forced-Chosen effect (e.g., Hampton, 2001) showing that performance is better on trials in which the UR is available, but not chosen, 
compared to trials in which the UR is not available. This has been interpreted as showing that animals gain a benefit from having the UR even when they do not use it, presumably because when they do not use it they are then more confident or more certain in their primary response than if they are forced to make that primary response because there is no chance to use the UR. Both species showed this performance facilitation when the UR was present compared to when it was not, a further confirmation of at least some shared uncertainty-monitoring capacity between macaques and capuchins.

Smith et al. (2008) pointed out that the forced-chosen effect must be interpreted cautiously. The original Sparse-Dense uncertainty task (e.g., Smith et al., 1997), from which the present tasks are derived, illustrates this point. That task presents a single stimulus for perceptual classification, in a fixed stimulus environment wherein the discrimination breakpoint is also fixed. Under these restrictive circumstances, Smith et al. (2008) showed that the forcedchosen effect can arise nonmetacognitively, based only on animals' responses to their firstorder subjective impressions of each stimulus as it is presented. If an animal simply chooses to only complete trials that present a strong subjective Sparse or Dense impression, accuracy will be high, and higher than in the forced condition in which all trials must be accepted, because for strong impressions it is unlikely that perceptual error from a trial of the opposite class could have produced that strong a counter impression. In contrast, the present tasks presented stimuli organized at 20 different absolute size levels. The stimulus landscape was not fixed. The absolute level of the discrimination breakpoint was not, either. Accordingly, the limitation that Smith et al. (2008) placed on interpreting the forced-chosen effect would not apply in this task. That limitation was also never meant to apply to the metamemory research in Hampton (2001).

Our preferred interpretation of the results is that the $16.67 \%$ guessing-correct percentage affected the decisional strategies of macaques and capuchins in our tasks, making primary response choices under difficult circumstances less advantageous and making uncertainty responding more advantageous. This may have affected capuchins more dramatically, because they were —on the floor $\|$ for uncertainty responding in earlier research, with more room to move higher, and because they may be risk tolerant and quite willing to make primary responses on the 50:50 reinforcement schedule characteristic of previous research (e. g, Beran et al., 2009). However, there are other possible interpretations of our results. For example, the inclusion of six possible stimulus choices in a variable stimulus environmentwith the response rule Choose the Largest—changes the basic psychophysical uncertainty task in intriguing ways. It makes the task a relational-judgment task. It requires the perceiver not to depend on first-order perceptual impressions of single stimuli. It dictates instead a perceptual- differencing strategy (e.g., MacMillan \& Creelman, 1991). For these reasons, it also probably elevates cognitively the psychophysical uncertainty task as has also been discussed in research with macaques (Shields et al., 1997). This elevation of the task's cognitive level could have also helped foster capuchins' uncertainty responding in the sixstimulus task. We discount the possibility that somehow we found coincidentally a particular perceptual dimension - size - that fostered capuchins' uncertainty responding. We know of no reason why this would be, whereas there are strong theoretical reasons why the structural changes we made to our task might have had a fostering effect. Nonetheless, one could in future research positively confirm these structural fostering effects by running capuchins 
alternatingly in two-and six-stimulus effects, examining the fostering effects within one perceptual continuum.

Our conclusion is that capuchin monkeys remain reluctant but capable users of an uncertainty response. It seems clear that they do not approach the general levels of proficient uncertainty responding seen in macaque monkeys, and the reasons for this are still not fully clear. However, it does seem clear that risk aversion may be a productive thing to consider in the development of future tasks for use with this species. We know relatively little about differences in risk aversion between rhesus monkeys and capuchin monkeys, and so additional work to assess such differences in parallel to additional work on relative differences in uncertainty monitoring seems prudent.

The present findings may seem to subtly alter the present theoretical debate in the animalmetacognition literature. Previously, the failure of capuchins to make uncertainty responses in diverse tasks appeared to strengthen the idea that macaques display a form of nonassociative metacognitive monitoring (e.g., Smith, Beran, Couchman, Coutinho, \& Boomer, 2009). The idea was that capuchins, who are not associatively challenged in any way, would easily make uncertainty responses if those responses were associative. The present results show that this argument from exclusion must now be made less strongly regarding capuchins. This new development simply shows the continuing progress in this active area. At present, the exclusion logic could still be grounded in the performances of other vertebrate species, especially pigeons. However, our position would be very supportive toward research on other species to disprove those discontinuities, and even toward positive results that did disprove those discontinuities.

Indeed, understanding the evolutionary foundations of human metacognition requires a comparative approach like that illustrated in this and related articles, because it is unlikely that human metacognition appeared in its full form, and appeared without precursors in the behavioral repertoires of other species (Smith, 2009; Smith, Couchman, \& Beran, 2013). Thus, clarifying the empirical picture of the phylogenetic distribution of abilities such as uncertainty monitoring in the vertebrates is important, as are comparisons across tasks but within species. Although the evidence is mounting that animals do show performances (in some cases) that reflect uncertainty monitoring, and that may even reflect metacognition, we still have only a limited survey with only a limited number of species. Beyond the primates, data exist only for a dolphin (Smith, Schull, Strote, McGee, Egnor, \& Erb. 1995), rats (Foote \& Crystal, 2007, 2012), bantams (Nakamura, Watanabe, Betsuyaku, \& Fujita, 2011) and pigeons (Adams \& Santi, 2011; Castro \& Wasserman, 2013; Iwasaki et al., 2013; Nakamura et al., 2011; Roberts et al., 2009; Sole, Shettleworth, \& Bennett, 2003; Sutton \& Shettleworth, 2008; Zentall \& Stagner, 2010). Even within the primates, researchers have mainly tested rhesus monkeys and apes, with some assessments of capuchin monkeys. No other New World species have been tested, and notably lacking are data from baboons, other macaque species, and other Old World primates. Those data are needed to help illuminate the phylogenetic map of potentially metacognitive abilities, and to better situate the apparent difference between rhesus monkeys and capuchins, even if that difference now appears more one of degree than one of kind. 


\section{Acknowledgments}

This research was funded by NIH grants HD061455 and HD060563 and by NSF grant BCS0956993.

\section{References}

Adams A, Santi A. Pigeons exhibit higher accuracy for chosen memory tests than for forced memory tests in duration matching-to-sample. Learning and Behavior. 2011; 39:1-11. [PubMed: 21264568]

Balcomb FK, Gerken L. Three-year-old children can access their own memory to guide responses on a visual matching task. Developmental Science. 2008; 11:750-760. [PubMed: 18801131]

Basile BM, Hampton RR, et al. Metacognition as discrimination: Commentary on Smith. Journal of Comparative Psychology. 2013 in press.

Basile BM, Hampton RR, Suomi SJ, Murray EA. An assessment of memory awareness in tufted capuchin monkeys (Cebus apella). Animal Cognition. 2009; 12:169-180. [PubMed: 18712532]

Benjamin AS, Bjork RA, Schwartz BL. The mismeasure of memory: When retrieval fluency is misleading as a metacognitive index. Journal of Experimental Psychology: General. 1998; 127:5568. [PubMed: 9503651]

Beran MJ. Rhesus monkeys (Macaca mulatta) succeed on a computerized test designed to assess conservation of discrete quantity. Animal Cognition. 2007; 10:37-45. [PubMed: 16868737]

Beran MJ. Capuchin monkeys (Cebus apella) succeed in a test of quantity conservation. Animal Cognition. 2008; 11:109-116. [PubMed: 17549530]

Beran MJ, Evans TA, Klein ED, Einstein GO. Rhesus monkeys (Macaca mulatta) and capuchin monkeys (Cebus apella) remember future responses in a computerized task. Journal of Experimental Psychology: Animal Behavior Processes. 2012; 38:233-243. [PubMed: 22545901]

Beran MJ, Parrish AE. Sequential responding and planning in capuchin monkeys (Cebus apella). Animal Cognition. 2012; 15:1085-1094. [PubMed: 22801861]

Beran MJ, Parrish AE. Visual nesting of stimuli affects rhesus monkeys' (Macaca mulatta) quantity judgments in a bisection task. Attention, Perception, \& Psychophysics. 2013; 75:1243-1251.

Beran MJ, Smith JD. Information seeking by rhesus monkeys (Macaca mulatta) and capuchin monkeys (Cebus apella). Cognition. 2011; 120:90-105. [PubMed: 21459372]

Beran MJ, Smith JD, Coutinho MVC, Couchman JJ, Boomer J. The psychological organization of uncertainty $\|$ responses and -middle $\|$ responses: A dissociation in capuchin monkeys (Cebus apella). Journal of Experimental Psychology: Animal Behavior Processes. 2009; 35:371-381. [PubMed: 19594282]

Beran MJ, Smith JD, Perdue BM. Language-trained chimpanzees name what they have seen, but look first at what they have not seen. Psychological Science. 2013; 24:660-666. [PubMed: 23508741]

Beran MJ, Smith JD, Redford JS, Washburn DA. Rhesus macaques (Macaca mulatta) monitor uncertainty during numerosity judgments. Journal of Experimental Psychology: Animal Behavior Processes. 2006; 32:111-119. [PubMed: 16634654]

Call J. Do apes know that they could be wrong? Animal Cognition. 2010; 13:689-700. [PubMed: 20306102]

Call J, Carpenter M. Do apes and children know what they have seen? Animal Cognition. 2001; 4:207-220.

Carruthers P. Meta-cognition in animals: a skeptical look. Mind and Language. 2008; 23:58-89.

Carruthers P. How we know our own minds: The relationship between mindreading and metacognition. Behavioral and Brain Sciences. 2009; 32:121-182. [PubMed: 19386144]

Carruthers P. Two concepts of metacognition. Journal of Comparative Psychology. in press.

Castro L, Wasserman EA. Information-seeking behavior: Exploring metacognitive control in pigeons. Animal Cognition. 2013; 16:241-254. [PubMed: 23065186]

Crystal JD, Foote AL. Metacognition in animals: Trends and challenges. Comparative Cognition and Behavior Reviews. 2009; 4:54-55.

Dunlosky, J.; Bjork, RA. Handbook of memory and metamemory. Psychology Press; New York: 2008. 
Evans TA, Beran MJ, Chan B, Klein ED, Menzel CR. An efficient computerized testing method for the capuchin monkey (Cebus apella): Adaptation of the LRC-CTS to a socially housed nonhuman primate species. Behavior Research Methods. 2008; 40:590-596. [PubMed: 18522071]

Flavell JH. Metacognition and cognitive monitoring: A new area of cognitive-developmental inquiry. American Psychologist. 1979; 34:906-911.

Foote AL, Crystal JD. Metacognition in the rat. Current Biology. 2007; 17:551-555. [PubMed: 17346969]

Foote AL, Crystal JD. Play it again || : A new method for testing metacognition in animals. Animal Cognition. 2012; 15:187-199. [PubMed: 21909935]

Fujita K. Metamemory in tufted capuchin monkeys (Cebus apella). Animal Cognition. 2009; 12:575585. [PubMed: 19242741]

Hampton RR. Rhesus monkeys know when they remember. Proceedings of the National Academy of Sciences. 2001; 98:5359-5362.

Hampton RR. Multiple demonstrations of metacognition in nonhumans: Converging evidence or multiple mechanisms? Comparative Cognition and Behavior Reviews. 2009; 4:17-28. [PubMed: 20046911]

Hampton RR, Zivin A, Murray EA. Rhesus monkeys (Macaca mulatta) discriminate between knowing and not knowing and collect information as needed before acting. Animal Cognition. 2004; 7:239246. [PubMed: 15105996]

Iwasaki S, Watanabe S, Fujita K. Do pigeons (Columba livia) seek information when they have insufficient knowledge? Animal Cognition. 2013; 16:211-221. [PubMed: 23065184]

Jozefowiez J, Staddon JER, Cerutti DT. Metacognition in animals: How do we know that they know? Comparative Cognition and Behavior Reviews. 2009; 4:29-39.

Koriat A, Goldsmith M. Memory in naturalistic and laboratory contexts: distinguishing the accuracyoriented and quantity-oriented approaches to memory assessment. Journal of Experimental Psychology: General. 1994; 123:297-315. [PubMed: 7931094]

Kornell N. Metacognition in humans and animals. Current Directions in Psychological Science. 2009; 18:11-15.

Kornell N. Where is the - metall in animal metacognition? Journal of Comparative Psychology. 2013

Kornell N, Son LK, Terrace HS. Transfer of metacognitive skills and hint seeking in monkeys. Psychological Science. 2007; 18:64-71. [PubMed: 17362380]

Le Pelley ME. Metacognitive monkeys or associative animals? Simple reinforcement learning explains uncertainty in nonhuman animals. Journal of Experimental Psychology. Learning, Memory, and Cognition. 2012; 38:686-708.

Le Pelley ME. Primate polemic: Commentary on Smith, Couchman and Beran. Journal of Comparative Psychology. 2013 in press.

Macmillan, NA.; Creelman, CD. Detection theory: A user's guide. Cambridge University Press; Cambridge, UK: 1991.

Marsh HL, MacDonald SE. Information seeking by orangutans: A generalized search strategy? Animal Cognition. 2012; 15:293-304. [PubMed: 21918872]

Marsh HL, MacDonald SE. Orangutans (Pongo abelii) — play the odds $\|$ : Information-seeking strategies in relation to cost, risk, and benefit. Journal of Comparative Psychology. 2012; 126:263278. [PubMed: 22023265]

Nakamura N, Watanabe S, Betsuyaku T, Fujita K. Do birds (pigeons and bantams) know how confident they are of their perceptual decisions? Animal Behaviour. 2011; 14:83-93.

Nelson, TO., editor. Metacognition: Core readings. Allyn and Bacon; Toronto: 1992.

Paukner A, Anderson JR, Fujita K. Redundant food searches by capuchin monkeys (Cebus apella): A failure of metacognition? Animal Cognition. 2006; 9:110-117. [PubMed: 16184375]

Richardson WK, Washburn DA, Hopkins WD, Savage-Rumbaugh ES, Rumbaugh DM. The NASA/LRC Computerized Test System. Behavior Research Methods, Instruments, and Computers. 1990; 22:127-131. 
Roberts WA, Feeney MC, McMillan N, MacPherson K, Musolino E, Petter M. Do pigeons (Columba livia) study for a test? Journal of Experimental Psychology: Animal Behavior Processes. 2009; 35:129-142. [PubMed: 19364222]

Scheck P, Nelson TO. Lack of pervasiveness of the underconfidence-with-practice effect: Boundary conditions and an explanation via anchoring. Journal of Experimental Psychology: General. 2005; 134:124-128. [PubMed: 15702968]

Schwartz BL. Working memory load differentially affects tip-of-the-tongue states and feeling-ofknowing judgments. Memory \& Cognition. 2008; 36:9-19. [PubMed: 18323058]

Shields WE, Smith JD, Washburn DA. Uncertain responses by humans and rhesus monkeys (Macaca mulatta) in a psychophysical same-different task. Journal of Experimental Psychology: General. 1997; 126:147-164. [PubMed: 9163934]

Smith JD. The study of animal metacognition. Trends in Cognitive Sciences. 2009; 13:389-396. [PubMed: 19726218]

Smith, JD.; Beran, MJ.; Couchman, JJ. Animal metacognition.. In: Zentall, T.; Wasserman, E., editors. Comparative cognition: Experimental explorations of animal intelligence. Oxford University Press; Oxford, UK: 2012. p. 282-304.

Smith JD, Beran MJ, Couchman JJ, Coutinho MVC. The comparative study of metacognition: Sharper paradigms, safer inferences. Psychonomic Bulletin and Review. 2008; 15:679-691. [PubMed: 18792496]

Smith JD, Beran MJ, Couchman JJ, Coutinho MVC, Boomer J. The curious incident of the capuchins. Comparative Cognition and Behavior Reviews. 2009; 4:47-50.

Smith JD, Beran MJ, Redford JS, Washburn DA. Dissociating uncertainty responses and reinforcement signals in the comparative study of uncertainty monitoring. Journal of Experimental Psychology: General. 2006; 135:282-297. [PubMed: 16719654]

Smith JD, Couchman JJ, Beran MJ. Animal metacognition: A tale of two comparative psychologies. Journal of Comparative Psychology. in press a.

Smith JD, Couchman JJ, Beran MJ. Animal metacognition: A tale of two comparative psychologies: Reply to commentaries. Journal of Comparative Psychology. in press b.

Smith JD, Coutinho MVC, Church BA, Beran MJ. Executive-attentional uncertainty responses by rhesus macaques (Macaca mulatta). Journal of Experimental Psychology: General. 2013; 142:458475. [PubMed: 22889164]

Smith JD, Redford JS, Beran MJ, Washburn DA. Rhesus monkeys (Macaca mulatta) adaptively monitor uncertainty while multi-tasking. Animal Cognition. 2010; 13:93-101. [PubMed: 19526256]

Smith JD, Schull J, Strote J, McGee K, Egnor R, Erb L. The uncertain response in the bottlenosed dolphin (Tursiops truncatus). Journal of Experimental Psychology: General. 1995; 124:391-408. [PubMed: 8530911]

Smith JD, Shields WE, Allendoerfer KR, Washburn WA. Memory monitoring by animals and humans. Journal of Experimental Psychology: General. 1998; 127:227-250. [PubMed: 9742715]

Smith JD, Shields WE, Schull J, Washburn DA. The uncertain response in humans and animals. Cognition. 1997; 62:75-97. [PubMed: 8997171]

Sole LM, Shettleworth SJ, Bennett PJ. Uncertainty in pigeons. Psychonomic Bulletin and Review. 2003; 10:738-745. [PubMed: 14620372]

Suda-King C. Do orangutans (Pongo pygmaeus) know when they do not remember? Animal Cognition. 2008; 11:21-42. [PubMed: 17437141]

Sutton JE, Shettleworth SJ. Memory without awareness: Pigeons do not show metamemory in delayed matching to sample. Journal of Experimental Psychology: Animal Behavior Processes. 2008; 34:266-282. [PubMed: 18426309]

Washburn DA, Gulledge JG, Beran MJ, Smith JD. With his memory magnetically erased, a monkey knows he is uncertain. Biology Letters. 2010; 6:160-162. [PubMed: 19864272]

Washburn DA, Smith JD, Shields WE. Rhesus monkeys (Macaca mulatta) immediately generalize the Uncertain response. Journal of Experimental Psychology: Animal Behavior Processes. 2006; 132:185-189. [PubMed: 16634662] 
Zentall TR, Stagner JP. Pigeons prefer conditional stimuli over their absence: A comment on Roberts et al. Journal of Experimental Psychology: Animal Behavior Processes. 2010; 2009; 36:506-509. [PubMed: 20718554] 

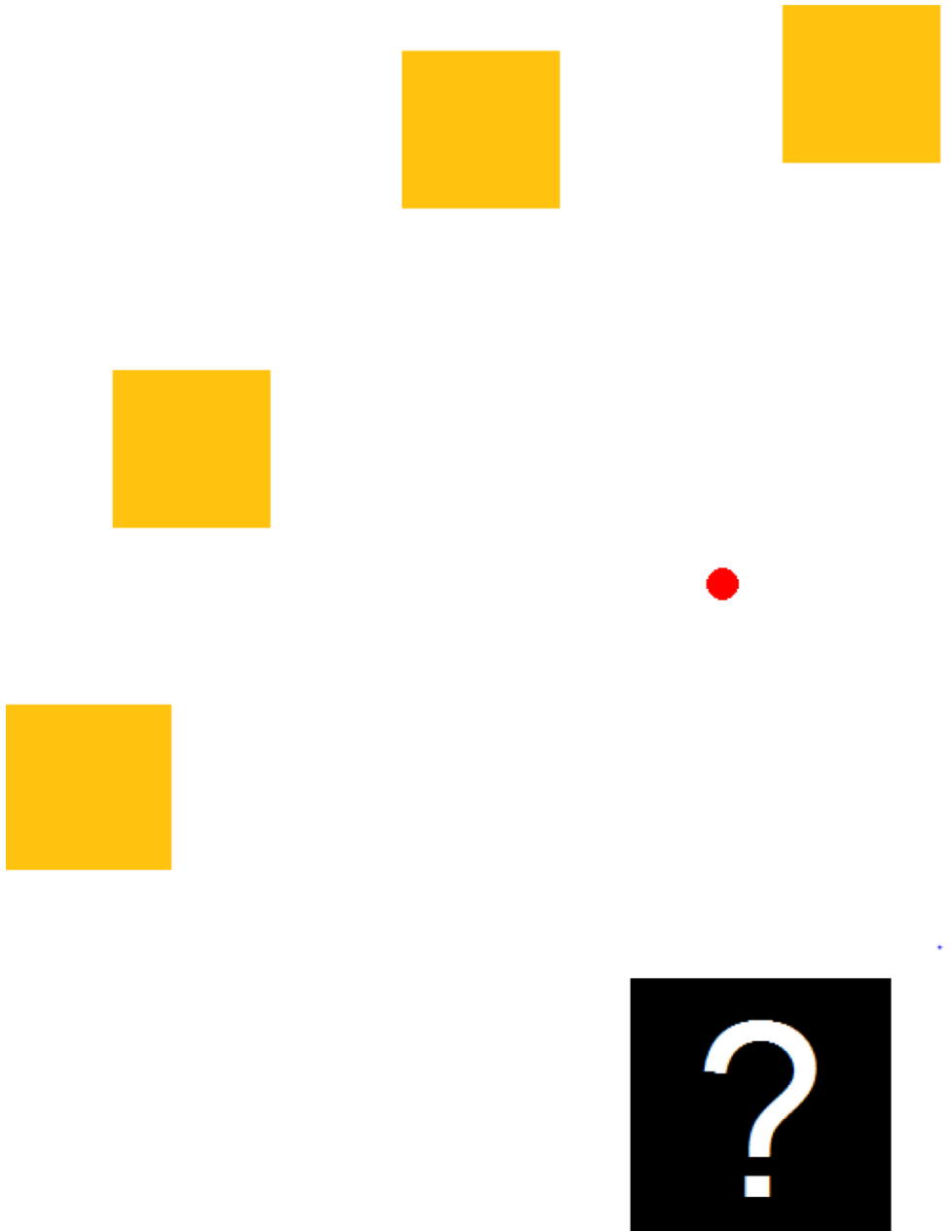

Figure 1.

A size-discrimination trial illustrated. The squares were presented in an orange color, and the largest had to be selected for food reward. Here, the largest square is to the bottom left. The ? is the uncertainty response. 


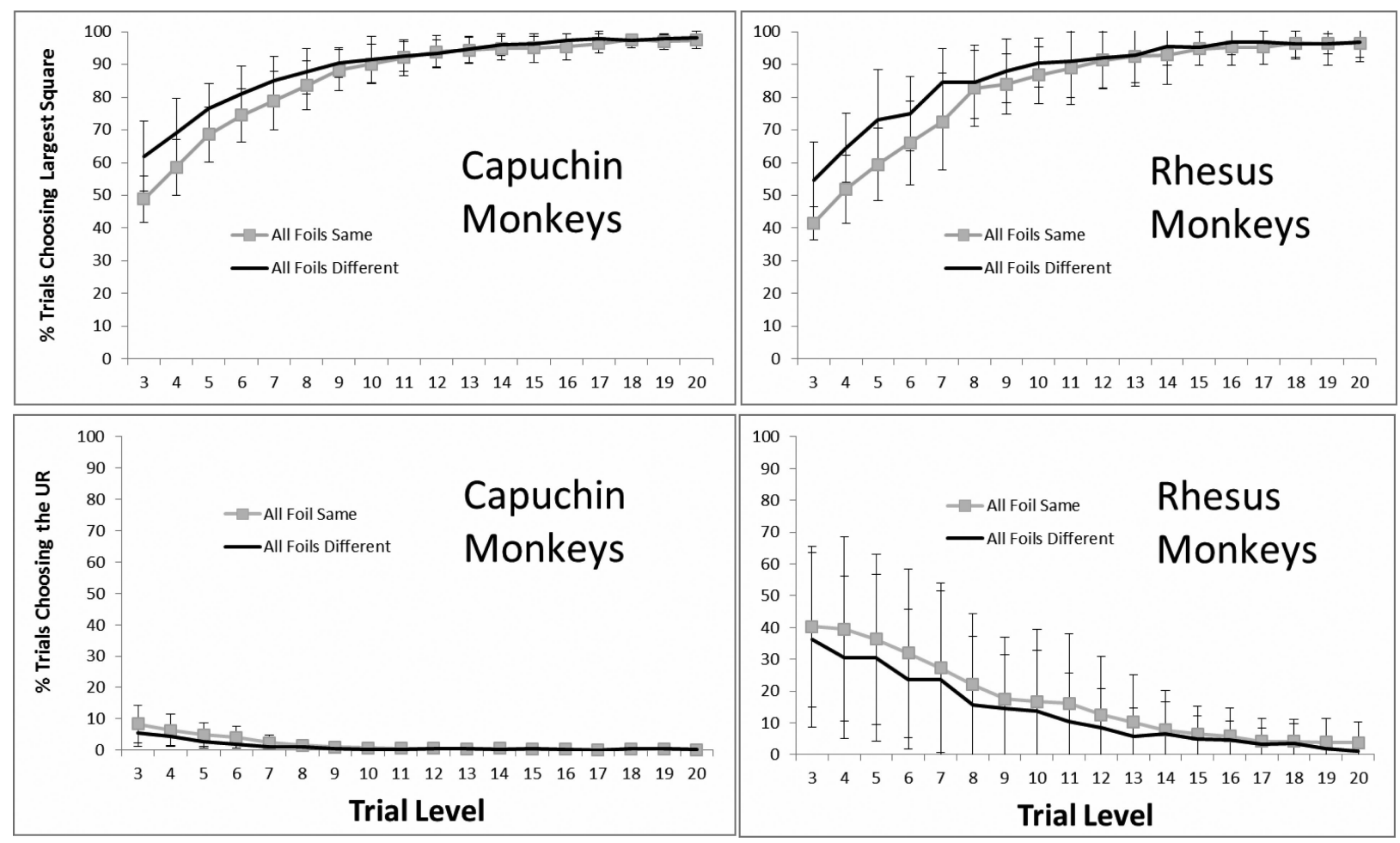

Figure 2.

Performance of each species as a function of trial level and condition. Error bars show 95\% confidence intervals. 

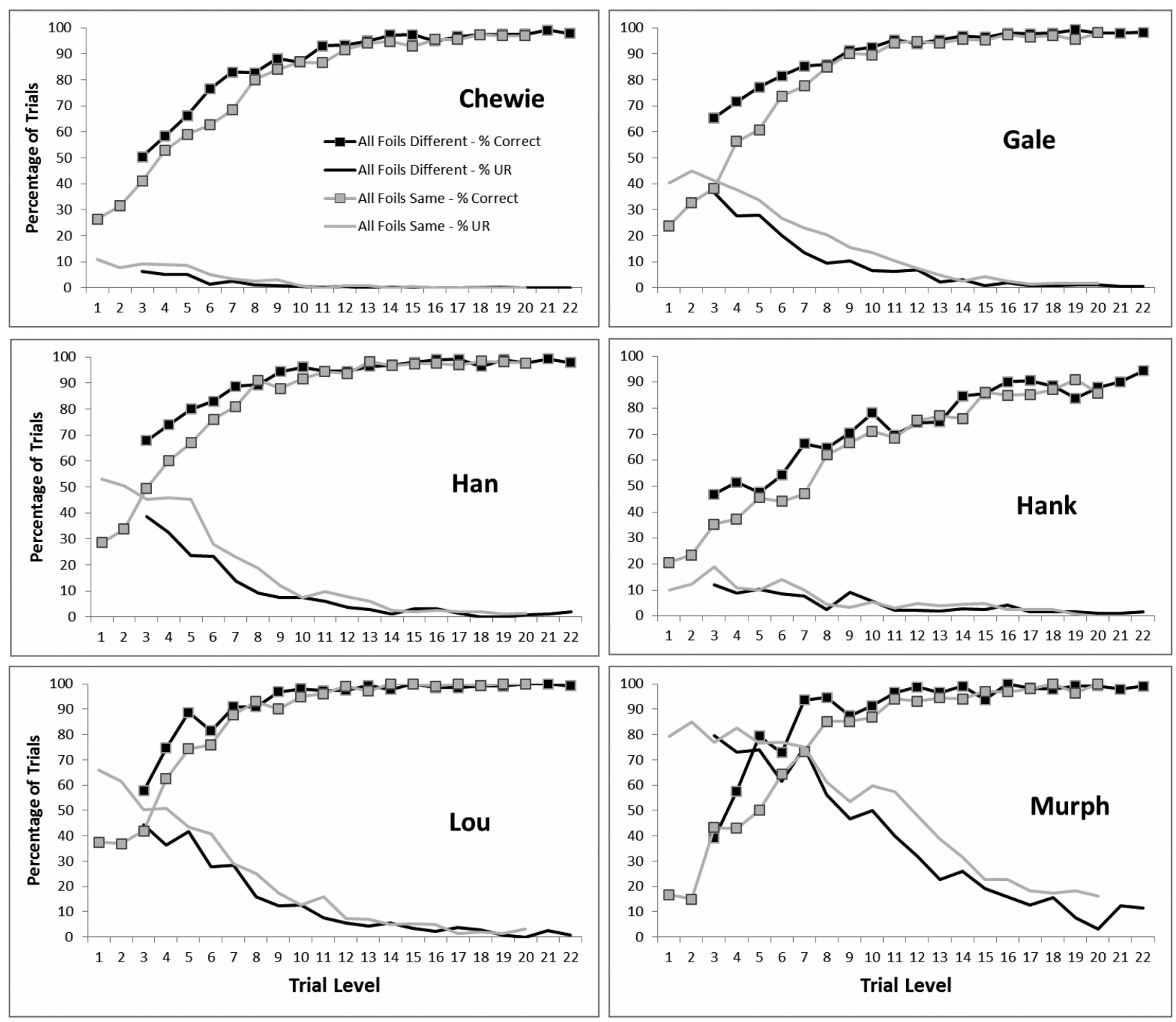

Figure 3.

Data from each rhesus monkey. The legend for the lines is shown in the top left graph. 

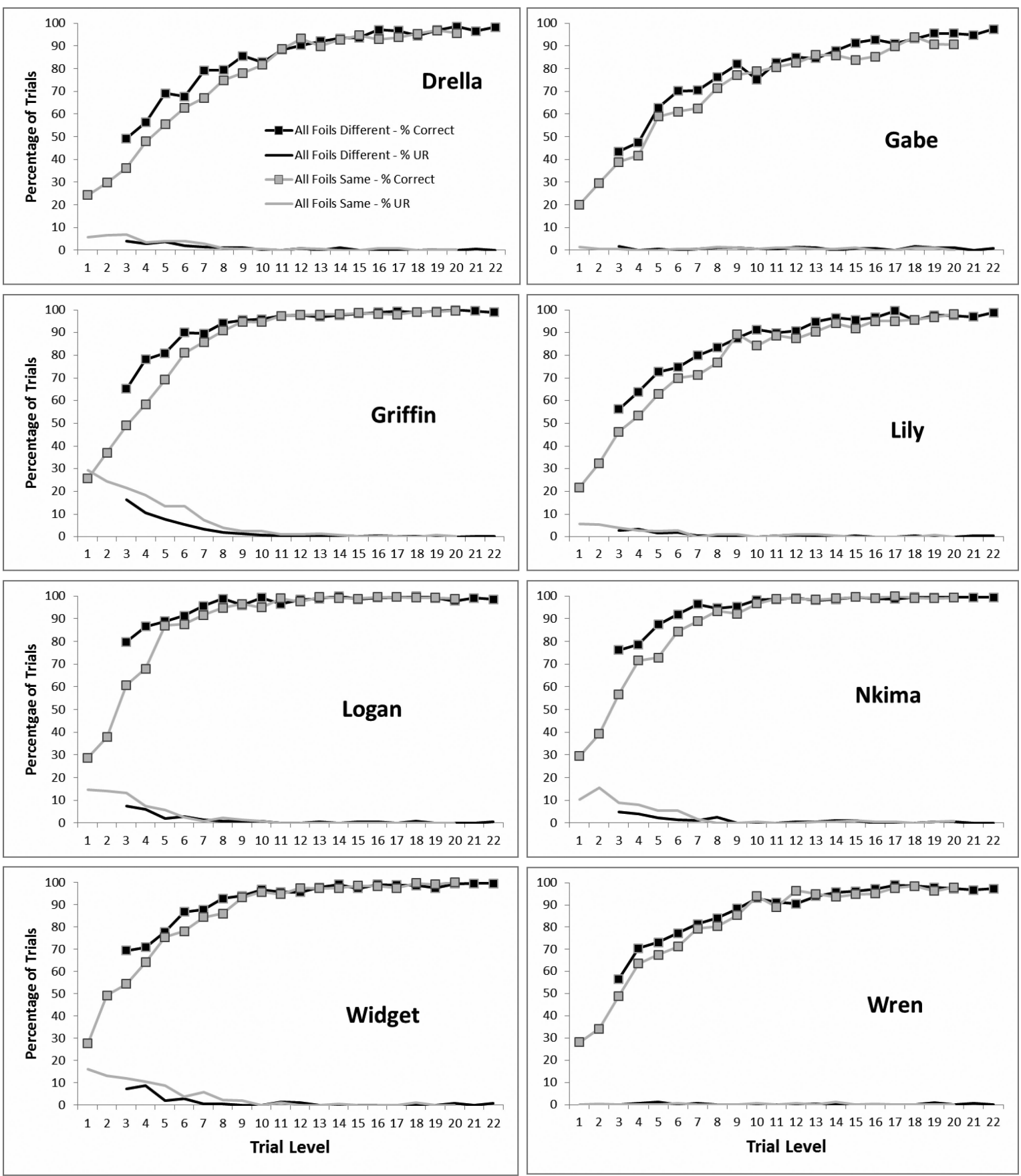

Figure 4.

Data from each capuchin monkey, as shown in Figure 3.

J Exp Psychol Anim Learn Cogn. Author manuscript; available in PMC 2015 July 01. 

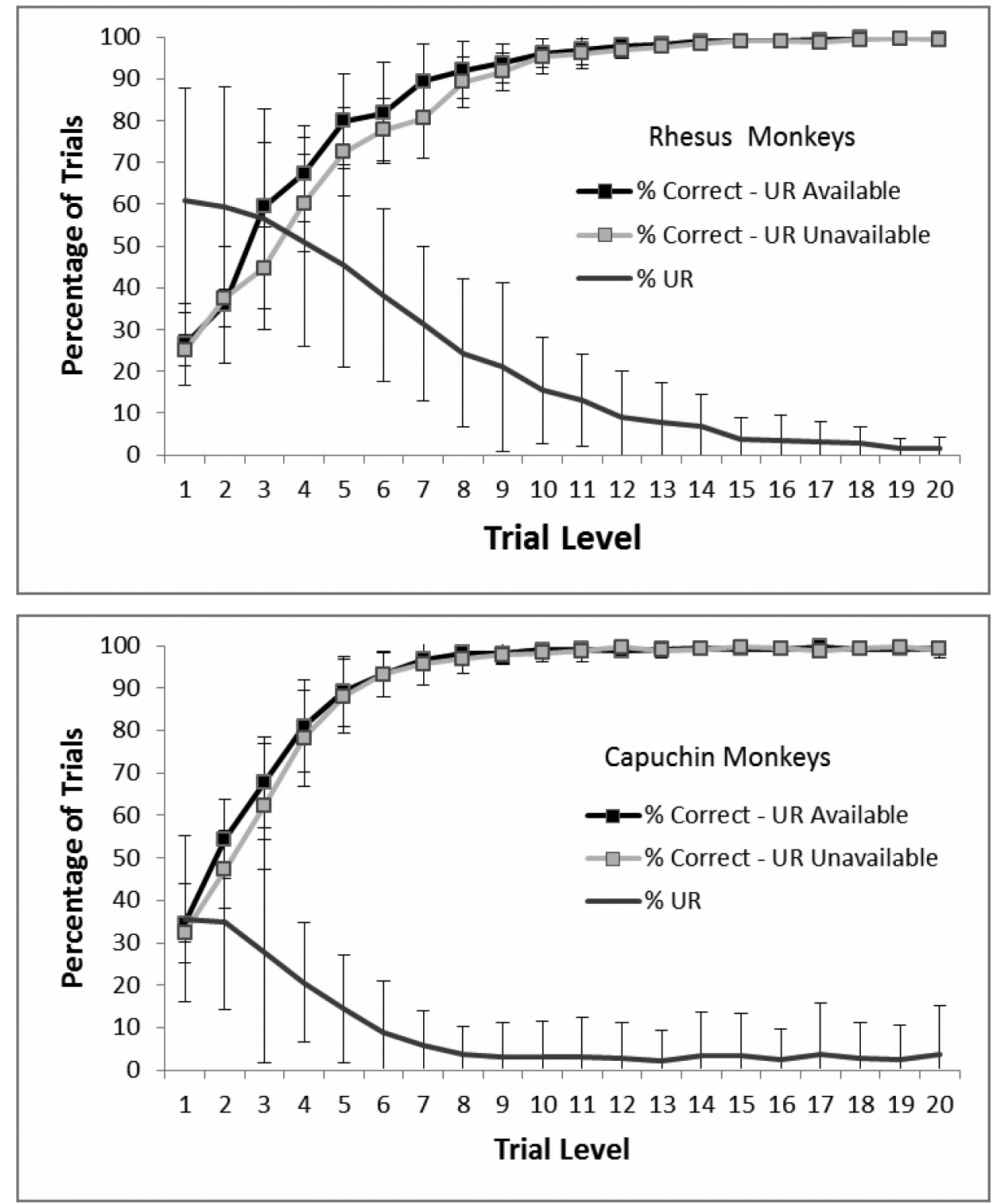

Figure 5.

Performance of each species as a function of trial level and condition (UR available or UR not available). Error bars show 95\% confidence intervals. 

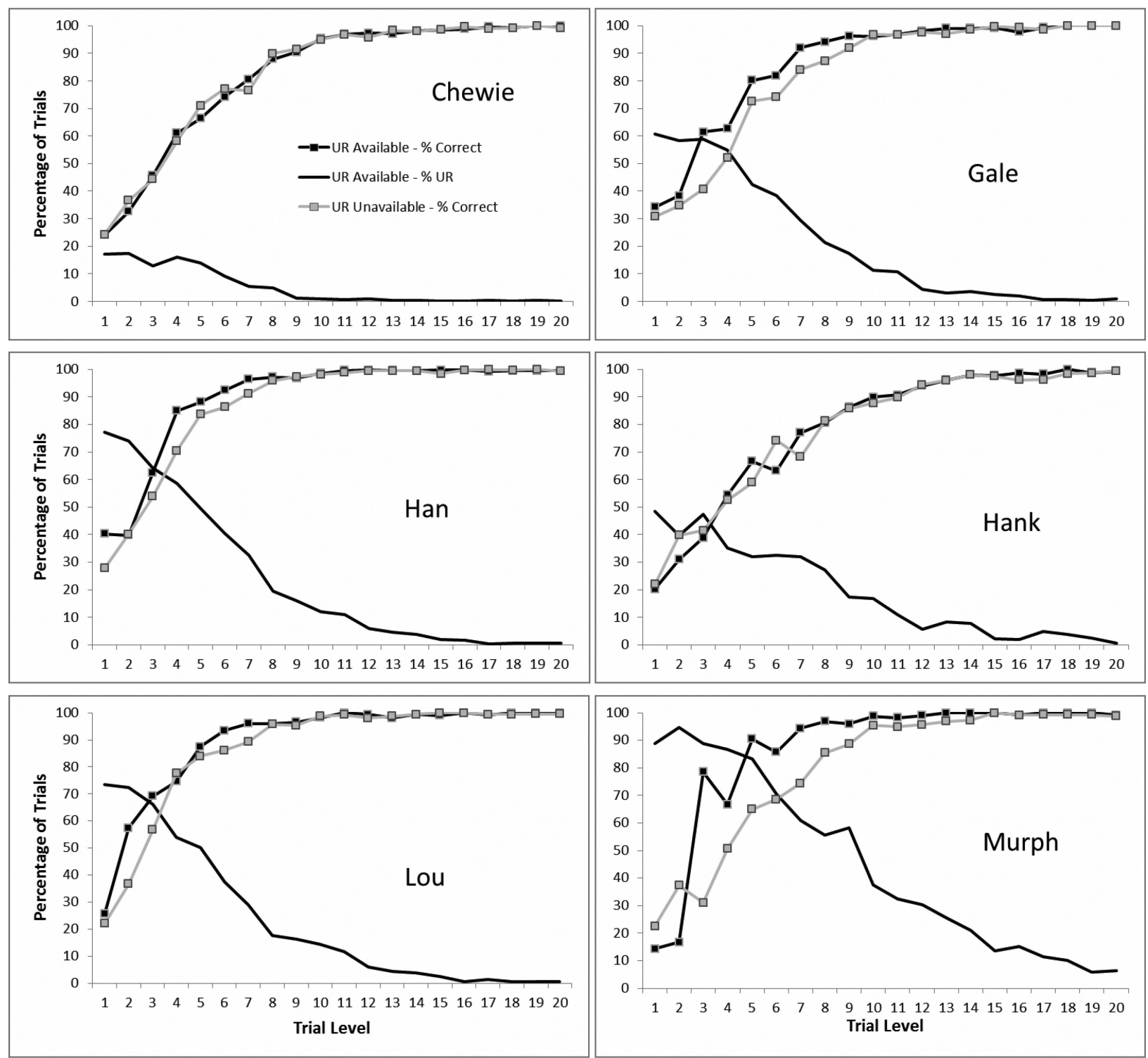

Figure 6.

Data from each rhesus monkey. The legend for the lines is shown in the top left graph.

J Exp Psychol Anim Learn Cogn. Author manuscript; available in PMC 2015 July 01. 

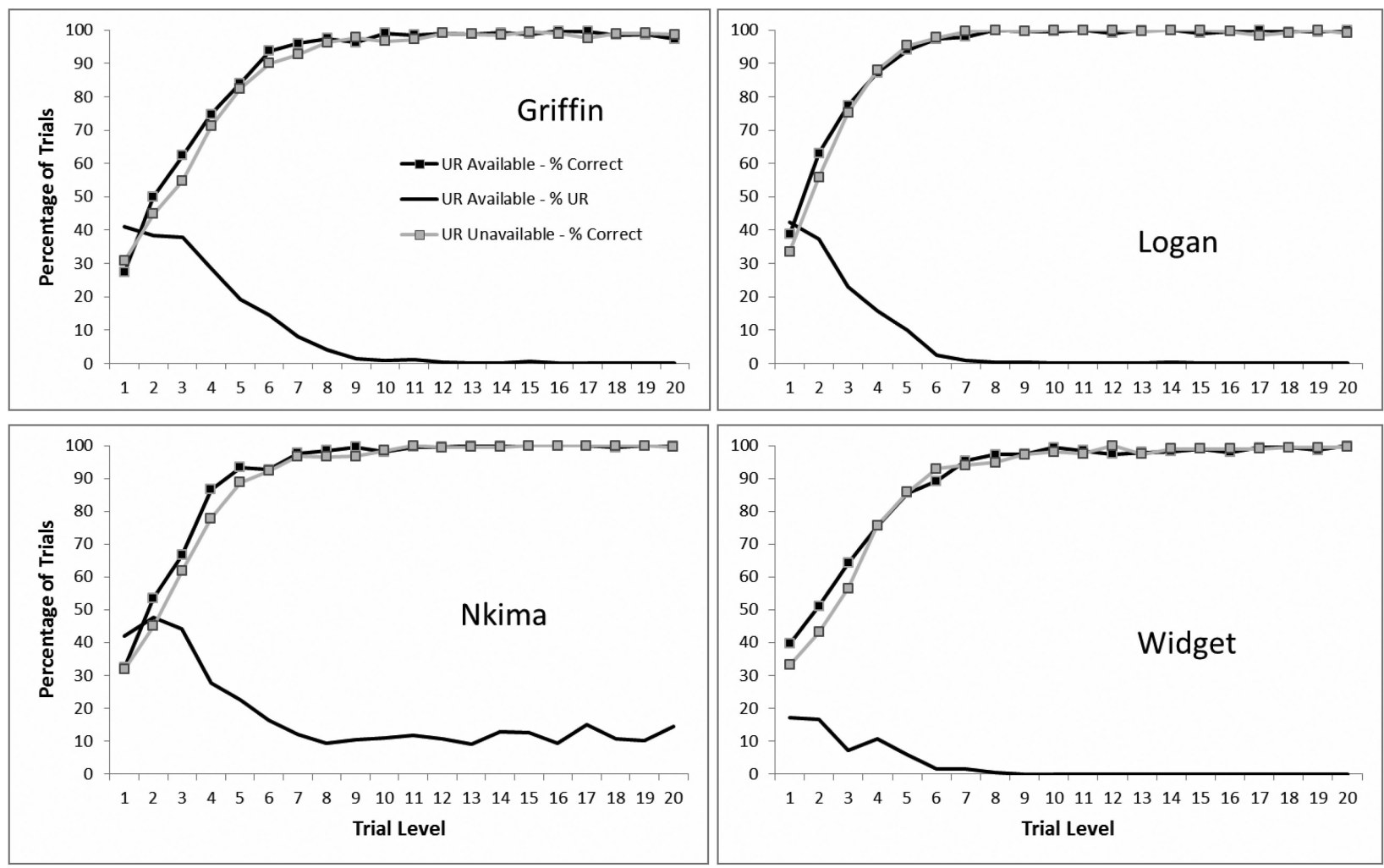

Figure 7.

Data from each capuchin monkey, as shown in Figure 6. 


\section{Table 1}

Correlations between the percentage of trials correct and the percentage of trials in which the UR was selected.

\begin{tabular}{|l|c|c|c|c|c|c|}
\hline & \multicolumn{4}{|c|}{ Experiment 1 } & \multicolumn{2}{c|}{ Experiment 2 } \\
\hline Rhesus Monkeys & \multicolumn{2}{|c|}{ All Foils Different } & \multicolumn{2}{c|}{ All Foils Same } & \multicolumn{2}{c|}{ UR Available } \\
\hline & $\mathrm{N}$ & $\mathrm{R}$ & $\mathrm{N}$ & $\mathrm{R}$ & $\mathrm{N}$ & $\mathrm{R}$ \\
\hline Chewie & 7294 & $-.96^{*}$ & 7137 & $-.958^{*}$ & 4730 & $-.953^{*}$ \\
\hline Gale & 5825 & $-.984^{*}$ & 5954 & $-.946^{*}$ & 5801 & $-.916^{*}$ \\
\hline Han & 5811 & $-.985^{*}$ & 5606 & $-.952^{*}$ & 7562 & $-.877^{*}$ \\
\hline Hank & 2428 & $-.837^{*}$ & 2387 & $-.86^{*}$ & 3068 & $-.942^{*}$ \\
\hline Lou & 2689 & $-.865^{*}$ & 2695 & $-.949 *$ & 3405 & $-.866^{*}$ \\
\hline Murph & 2538 & $-.74 *$ & 2639 & $-.829 *$ & 2773 & $-.706^{*}$ \\
\hline
\end{tabular}

\begin{tabular}{|l|c|c|c|c|c|c|}
\hline Capuchin Monkeys & \multicolumn{2}{|c|}{ All Foils Different } & \multicolumn{2}{c|}{ All Foils Same } & \multicolumn{2}{c|}{ UR Available } \\
\hline & $\mathrm{N}$ & $\mathrm{R}$ & $\mathrm{N}$ & $\mathrm{R}$ & $\mathrm{N}$ & $\mathrm{R}$ \\
\hline Drella & 5971 & $-.924^{*}$ & 6243 & $-.948^{*}$ & Not tested & Not tested \\
\hline Gabe & 3944 & .071 & 3938 & -.007 & Not tested & Not tested \\
\hline Griffin & 8956 & $-.991^{*}$ & 8959 & $-.988^{*}$ & 6155 & $-.936^{*}$ \\
\hline Lily & 3958 & $-.899^{*}$ & 3958 & $-.935^{*}$ & Not tested & Not tested \\
\hline Logan & 4836 & $-.936^{*}$ & 4810 & $-.968^{*}$ & 3987 & $-.972^{*}$ \\
\hline Nkima & 3792 & $-.928^{*}$ & 3913 & $-.944^{*}$ & 4417 & $-.915^{*}$ \\
\hline Widget & 3327 & $-.90^{*}$ & 3415 & $-.978^{*}$ & 3476 & $-.969^{*}$ \\
\hline Wren & 3888 & -.218 & 3918 & .129 & Not tested & Not tested \\
\hline
\end{tabular}

Note. Asterisks indicate $p<.01$. 